\title{
The Nature-Culture Distinction in Disaster Studies: The Recent Petition for Reform as an Opportunity for New Thinking?
}

\author{
Gideon van Riet $^{1}$
}

Accepted: 15 December 2020/Published online: 22 January 2021

(C) The Author(s) 2021

\begin{abstract}
This article constructively challenges the often cited distinction between the so-called hazard and vulnerability perspectives in disaster studies. In a context of increasingly intertwined, dense, and complex socioecological dynamics, disaster scholars often hold onto an apparently untenable distinction between nature and culture, manifested as either a hazard or a vulnerability approach. This article maintains that the typically undesired approach (the hazard approach) is inherent to the preferred (vulnerability) perspective. The article builds on Oliver-Smith's (2013) critique of the magnitude of requirements placed upon practitioners given the full implications of the vulnerability perspective. Although critical of the vulnerability perspective, this article does not fundamentally disagree with the validity of its claims. Instead, by drawing on the pragmatist philosophy of Rorty (1989) and by demonstrating the potential value of posthumanism for disaster studies, I wish to argue for greater pragmatism within disaster scholarship. The article considers the recent petition or manifesto for disaster studies (Gaillard et al. 2019) for more inclusive disaster research as a potential opportunity to challenge the aforementioned nature-culture distinction in the field, as the petition signed by a number of disaster scholars outlines various concerns over the asymmetrical power relations between local and external researchers. These power relations have adverse consequences for the appropriateness of knowledge production in many contexts. I am primarily
\end{abstract}

Gideon van Riet

Gideon.vanriet@nwu.ac.za

1 School for Government Studies, North-West University, Potchefstroom 2531, Northwest Province, South Africa concerned with the very local level of disaster occurrence, where posthumanism might be most valuable.

Keywords Disaster studies · Nature-culture · Posthumanism · Pragmatist philosophy ·

Vulnerability perspective

\section{Introduction}

As disaster scholars, our concepts have served us well over the past approximately 50 years. Statements such as "taking the naturalness out of natural disasters" (O'Keefe et al. 1976), along with concepts such as vulnerability, mitigation, and preparedness have helped us understand and impress upon many policymakers that the causes of disasters are located in the everyday. Disasters are not discrete events that fall outside of the realities of human habitation of the planet. Although universally applicable to all types of disasters, this logic and its validity is epitomized by the gradual shift over the past half a century towards a general consensus whereby climate change is not only viewed as a challenge for humankind, but also is considered to be largely caused by humans (Lewis 1989; IPCC 2007).

This article offers a constructive response to what I deem to be the persistent nature-culture distinction in disaster studies. This distinction plays out as a division between the so-called "hazard" and "vulnerability" perspectives on disaster and hashtags such as \#NoNaturalDisasters. While this article still considers the vulnerability perspective the most plausible and comprehensive perspective on disasters, it is not without problems. As Oliver-Smith (2013) explains, the implications of the vulnerability perspective place incredible demands on 
researchers, practitioners, and politicians working across numerous increasingly dense and complex scales. It is therefore no surprise that assessments of success in disaster reduction have been less than inspiring. I therefore suggest that disaster studies, equipped with substantial theoretical tools, have reached a partial impasse at the level of practice. My contention is that part of this impasse relates to the nature-culture distinction, especially at the local level. The article draws on the recent petition for more inclusive disaster studies, a manifesto signed by numerous disaster scholars, among other arguments to illustrate this partial impasse (Gaillard et al. 2019). I also approach the petition as a potential opportunity to address the nature-culture distinction, where appropriate. I do this by arguing for the merits of a posthumanist approach to disaster studies, while still considering all approaches to the problem of disaster as subsumed by a principled pragmatism based on the philosophical work of Rorty (1989).

The article is structured as follows. The next section provides an overview and reading of the petition and its main objectives in which I argue that the petition is an important intervention. It is also evident that the disaster field has to some extent reached an impasse. In this section I add additional justifications for the notion of a partial contemporary impasse by emphasizing the practical limits of the vulnerability approach as it is often articulated. These limits relate to peculiar articulations of "social constructivism" and the scale at which "radical" agendas are pitched. The third section explains why we might inadvertently be perpetuating myths that ironically work against the logic of disaster reduction. Chief among these is the increasingly untenable distinction between nature and culture within disaster studies, given the complexity, density, and intertwined nature of global socioecological processes. The article then offers some suggestions for dealing with this complexity. The set of potential and contextually appropriate solutions, following an engagement with posthumanism, revolve around a pragmatic politics of wellbeing within a broadly defined ecology. The fourth section delves deeper into notions of philosophical pragmatism, as a basis for open and receptive thought and practice. This includes being open to some valuable approaches that have already emerged in disaster studies and, as is stated in the petition, promotes being open to local and non-Western perspectives. This change in vernacular, towards a singular ecology, informed by pragmatism, and posthumanism where appropriate, might alleviate some of the main stumbling blocks we currently face in disaster reduction.

\section{The Petition and Other Manifestations of Impasse}

The recent petition for more inclusive disaster reduction (Gaillard et al. 2019), sets out some admirable and arguably necessary objectives for disaster studies. In an era where coloniality as an enduring feature of the world after formal colonialism is increasingly being called out, this petition is a welcome intervention.

The current problem identified in the petition has many tentacles. There is a concern with greater respect for, and more reciprocal and authentic collaboration between, local communities and researchers (hereafter local researchers) and external researchers. Simply put, there ought to be less top-down and extractive research and more meaningful longer-term engagement that is locally led and collaborative between researchers at all levels. Currently, external researchers at best "discover" "new insights" that are aimed for publication in prestigious journals or at worst, these insights become a type of "conquest," where research is done about people for personal gain and not with and for people (Gaillard et al. 2019). This argument is in keeping with a long history of similar, yet often ignored, calls for meaningful local participation in disaster studies (Maskrey 1989).

According to the petition, Enlightenment thinking typically informs research problems and methodologies. Local ontologies and epistemologies are neglected, often because reviewers and experts are located in the West and because the primacy of English as a global academic language restricts access to such journals for nonnative speakers. Moreover, the pressures associated with career building often lead to publications that disempower local perspectives by framing local populations as a "vulnerable" exotic other. In this regard, Bankoff's (2001) critique of vulnerability as a type of orientalism, remains pertinent to this day. Furthermore, the petition holds that research agendas may be formed by foreign policy and development aid interests, when research grants are meant to promote the diplomatic and trade interests of donors, irrespective of the needs of local populations. As funding for research by local people typically does not exist, capacity building projects often manifest as a type of neocolonialism.

Quite refreshingly, the petition acknowledges that disaster research is overtly political and it is not detached from historical legacies, and one might add, their reiterations. Those who have committed to working on disaster reduction should understand the implications of the obligations they have undertaken. This commitment is already normative. It is therefore quite unclear what disaster reduction might entail apart from politics, broadly conceived as power and, as such, as deliberate and inadvertent 
influence, or the so-called third and fourth faces of power (Digeser 1992). Simply put, there is no such thing as empirical theory (as opposed to normative theory), as there is no context devoid of politics. The fourth face of power according to Digeser, as opposed to the other faces of power, is one which designates a form of power that is exercised also unintentionally. In the case of disaster reduction, the inclination is necessarily oriented more towards a deliberate politics. Finally, the petition holds that stories should be told to reflect local collaboration and leadership. These local stories, including research results, should be told in local languages too, so that knowledge is accessible to all who want and should be able to make use of it.

The petition also states particular demands and strategies for action that follow from the above-stated observations. These include, but are not limited to, greater respect for and trust in local researchers to set the agenda and lead research on matters that affect them. Strategies for achieving these objectives may be summarized as changes in what is researched and how and by whom it is researched. The implication is that external researchers stop assuming the role of experts. Instead, those who have most at stake should be able to shape the research and facilitate narratives that serve their needs and not that of external researchers. Local institutions should be encouraged to take the lead in determining research agendas. At the same time, local researchers should be encouraged to lead research projects, from designing proposals to collecting and analyzing data as well as (co)authoring publications.

The petition speaks directly to what I perceive to be a partial impasse in contemporary disaster studies. The problem of top-down policy convention-led disaster reduction is admonished by Lewis and Kelman (2012). This approach to disaster reduction has clearly not worked and others such as Wisner (2020) seem to agree. Such topdown disaster reduction could manifest as a type of performance of care, which suggests that something is being done, when the reality of disasters and susceptibility to hazards is quite complex and context specific. Van Riet (2017) argues that the very consensus principle of these conventions render a set of standardized concepts, objectives, and measures that are vague, and yet are deemed necessary for diverse real-life contexts. It is then up to national and lower level government structures to devise ways of implementing, at times extraordinarily ambitious, objectives such as the vague and all-encompassing notion of "reducing the underlying causes" of disasters. It is hardly surprising that global assessments of the Hyogo Framework for Action 2005-2015 (WCDRR 2005) and the subsequent Sendai Framework for Disaster Risk Reduction 2015-2030 (WCDRR 2015) have been found to be especially poor on this point (Wisner 2020). These "underlying risk factors" span numerous fields of study. Thus Wisner (2020, p. 8) notes, "there is more to successful implementation than the fulfilment of countable targets." Yet policies stemming from these conventions are inordinately ambitious and even developed countries struggle to "mainstream disaster reduction into development." This brings us to my more substantive critique of the vulnerability perspective in disaster studies. This critique relates to matters of scale, at times ambiguous readings of social constructivism, and the modes of intervention some contemporary readings of vulnerability leaves us with.

On the first point, we should acknowledge that there are different levels at which vulnerability reduction can take place. At the macro and meso levels, the above-mentioned problems with policy uniformity come into play. Political economy and institutional capacity are most significant at these levels. There has been much criticism of international funders and organizations, national governments, and local governments. There is much lamenting of our inability to deal with root causes and the drivers of vulnerability. One also continually gets the impression that blame is largely shifted to national policymakers and local government bureaucrats, who, granted, are often significantly to blame (see Wisner 2020). But this type of generalization of corruption being the destroyer in chief of "admirable policy" is only partially true. During the Cold War superpowers propped up newly independent, yet often corrupt, but loyal dictators. After the Cold War, neoliberal reforms have often rendered accountability for the delivery of public goods and services, including those related to disaster reduction, complicated at best (Wisner 2001; Van Riet 2017). Complaining about a lack of political will and capacity in lieu of more significant political action and simply reiterating, as we have been, that disasters are human-made, has not delivered the desired results. Two points should be considered here: (1) The underlying argument in the passages immediately above is one of social justice, which is important. But, it is also largely a generic imperative that extends far beyond disaster reduction; and (2) Blame seems to be the only tool available to the vulnerability perspective, when working at the macro and meso levels. While advocacy and pressure on corrupt and greedy contractors, bureaucrats, and leaders should not desist, we have to acknowledge that the success of this approach has been limited.

If we move down to the local level, the logic of social construction has often been deployed in imprecise terms. The notion that disasters or risk are socially constructed has become a major axiom of the field. Somewhat strangely, what most disaster scholars mean by "social construction" is quite different from the social sciences' perspective on the matter. Many social scientists would argue that the 
phrase "the social construction of risk" implies that risk is not real. One might cite the work of authors such as Dean (1998) and Higgs (1998), who espouse a governmentality approach to risk as a major strand of risk research. This perspective is ignored by many disaster scholars, who at the same time repeat phrases such as "disaster reduction is everyone's business." If this is the case, then how do we draw more social scientists towards the cause of disaster reduction? What many disaster scholars apparently mean when they speak of the social construction of risk is simply that disasters are made through human action in a material sense. But this is not Constructivism. I will return to the social scientific notion of social construction shortly. For now, continuing with the use of blame as a strategy in disaster studies, it is important to emphasize that the choices that lead to disaster, as Kelman (2020) illustrates, are typically not the choices of those who suffer the brunt of said disasters. So the most readily available tool of blame is not only inadequate at the micro level, as it is largely at higher levels, but it is also potentially unethical, when amounting to victim blaming.

The social scientific notion of constructivism relates to how humans through social interaction come to understand and find meaning in the world. Constructivism implies intersubjective processes, which may often lead to understandings that may cause vulnerability to disaster. But this matter should be approached with extreme caution, since invoking a notion of "false beliefs," as studies on risk perception often do, can be quite orientalist and ignorant; a function of the researcher's own subject position. At its worst this research holds that all that is apparently needed is for "ignorant" locals to be taught how to mend their ways. This theme in risk perception research, be it at the individual or "cultural" level, has remained very common (Flint and Luloff 2005; Waschinger et al. 2013; Xu et al. 2018). It has also been criticized among other reasons for objectifying people (Wisner 2019). Therefore, in keeping with the spirit of the petition, suspicions of dangerous interpretations of reality should be explored in collaboration with local researchers in an open-minded way.

There is another danger in invoking notions of false beliefs, when researchers' understanding of complexity is limited by a search for a type of telos (ultimate aim) associated with overcoming one potential risk. This danger is especially prevalent when we assume that we know more than we actually do. Statements like, "we know what the risks are. We just need to reduce vulnerability/risk" are exemplary in this regard (Wisner 2020, p. 3). This logic is based on a relatively static understanding of the social and the construction of reality and as I will elaborate in Sect. 3 the complex and dynamic interactions between the human and the nonhuman. This perspective risks recognizing and addressing one set of "false beliefs" associated with one particular hazard, while not realizing that other potential risks and social constructions are formed, continuously.

Conceptions of reality are fleeting. Too often this fact is underplayed by statements that suggest that all disasters are preventable. Within this paradigm some leading experts for whom I have immense respect have even gone as far as stating that hazards are not necessarily natural (Hewitt 1997; Kelman 2010). Based on the simplistic dichotomy between nature and culture implied in disaster studies, are we then to conclude that hazards are a function of culture; that they are human made, exclusively? Some appear to imply that they are. Notwithstanding the merits of the vulnerability perspective, as a form of resistance to the imposition of danger onto marginal populations, once we accept that there are many daily realities over which we have limited power-at least immediately_-we may be better placed to focus on what we can do to improve disaster reduction. In theory all disasters might very well be preventable, but in reality there is more than enough evidence that this does not happen. Blame, the most readily available tool to those of us espousing a vulnerability approach to disasters, is hardly an effective tool in the wake of imperfect knowledge and the power relations that permeate our socioecological realities.

Disaster reduction has largely failed as a top-down policy matter. In addition, it has also largely failed as an oversimplified top-down field of study. The petition has quite clearly pointed this out by emphasizing the urgent need for greater and more genuine collaboration with local researchers. In addition, the disaster risk field continues to reiterate the same generic argument of social vulnerability over and over again, without making major strides in disaster reduction. There still may be contexts where this general rhetorical device and even the more substantive concepts that have been developed under its rubric have value, for example by mobilizing people and resources. My argument, however, is that because the predominant view in contemporary disaster studies is that humans have near exclusive agency, and that this agency is largely independent of other physical elements in the world, we might need new and broader thinking on the problem of disaster.

\section{The Nature-Culture Distinction in Disaster Studies}

We live in a globalized and interlinked world. This statement is quite the truism. Statements such as these require more precise conceptualization, to avoid turning "globalization," "interconnectedness," "interlinked," and "the environment" into empty signifiers. Castells (1996) is one author who articulated a long-standing but useful concept to describe the network society as it was unfolding in the 
1990s. He used the concept of flows. These are cross border and subnational movements of people, goods, objects, and ideas. These ideas might include multilateral protocols on trade, finance, and the environment, to name only a few examples. The rules devised under the various rounds of the Global Agreement on Tariffs and Trade (GATT) and the World Trade Organization (WTO) have provided for the free flow of goods and services across borders. To this we may add bilateral treaties, such as the African Growth and Opportunity Act (AGOA), which is at times both a carrot and a stick for African countries. Intercontinental travel also has become far easier and so too migration and brain drain from and remittances to some countries. Moreover, global supply chains have benefitted from technological advances, as production moved to postFordism and just-in-time production. This has at times been detrimental to some countries that are unable to compete with others' wage levels. In the process, the ability of many people to protect themselves from all manner of harms, including hazards, is eroded. Macro level drivers of vulnerability such as these are hard to deny.

At the local level, urbanization reshapes the physical world. Based on a posthumanist logic, however, it might be stated that in this reshaping of the physical world, the physical world too gains agency and also directs flows. In the process, the built physical world, which has been developed onto a site previously presumed "natural," takes on a degree of immutability. These revised physical conditions and their agency leaves at risk communities and authorities with a limited set of available options for action, both in terms of what is conceivable and what is achievable. Often both these movements are largely unknown to humans and merely become part of the expedient activities of the everyday. In this regard, Freudenburg (1996, p. 49) points us to so-called "blind spots" in risk assessment. As we "do not know what we do not know," it is near impossible to ask all of the right questions in a given context. Consequently, placing a parameter around the notion of complexity is perhaps a bridge too far.

To insist that these manifold socioenvironmental changes are a function of increased vulnerability in light of preexisting hazards is to miss some of the detail at play in disaster creation. Human activities have always affected nature. At the same time nature and other agents associated with the increasingly popular notion of the "more than human," affects human behavior. This may happen even when we do not realize it. Furthermore, the "human" and the "natural" worlds, which affect each other, are already altered through previous interactions. Therefore, authors such as Latour (1993) and Haraway (2004), working on the more than human or posthumanism, have been arguing that there are no separate natural and human worlds. This position is not out of keeping with fieldwork in diverse
non-Western contexts from within many other disciplines. The close relationship between the latter and Latour's (1993) work is evident from the discussion in the following paragraph. Posthumanism does not mean after humans, but merely a break with some of the illusions of humanism. Most important among these is the idea that humans exercise completely independent agency, apart from the nonhuman world (Wolfe 2010). I am not the first to make this point in the context of disaster research. Also consider the important contribution by Katanha and Simatele (2019), who draw on a Zimbabwean case study to illustrate the point.

For the purposes of this article, I similarly draw on the work of Latour (1993) to concisely illustrate a South African example. Latour (1993) argues that we have never been modern, as modern in the sense of Enlightenment thought is distinguished from premodern societies through a "purification" exercise whereby nature and culture are separated. Purification opens "nature" to conquest through science and by extension culture. At the same time, "translation" takes place, whereby hybrid human and nonhuman categories are created and integrated into the "nature" that has been rendered amenable to human manipulation. Purification and translation obscure what Latour (1993) calls quasi-objects, between narrow notions of nature and culture. These objects may include living things and their agency, such as animals and microbes. They may also include inanimate objects, which, as I have explained above, may also direct flows. In the context of disaster studies, quasi-objects may help explain why and how people continue to live in dangerous conditions.

Here I use the example of informal settlement fire and flood risk in Ikageng, South Africa. These observations are based on my experiences during recent qualitative research in that area. Conventionally, informal settlement fires may be blamed on authorities and reduced to human vulnerability as people settle too close to each other on account of "false beliefs." At the same time overgrown bushes are left to proliferate due to "poor service delivery" by local government. While all of this is true, it misses the agency exerted by and through the individual shack, built on an unzoned area as a means of obtaining shelter. The daily reality for occupants of these structures is one where the state is not delivering homes at an acceptable rate. The local municipality is bankrupt and unable to keep bushes at bay. Here the object of the self-built home and those next to it physically and socially constructed onto nature has more meaning in how people live their daily lives than blanket statements about human vulnerability and human causation have for the most part revealed. These structures take on a degree of immutability and they partially direct the flow of people, unsafe heating practices as there is no electricity, and plant growth, for example. The subsequent 
growth of shrubs may, for example, direct the spread of fire. Where these bushes are cut, less absorbent, denuded surfaces speed up the flow of water and initiate erosion. Moreover, the presence of some of these structures leads to residents building more structures. All of these processes usher in new iterations of the agential physical world including elements between nature and culture. The key here, following the ethos of the petition is to engage in depth with local residents to uncover how the relationship between humans and objects affect risk. Additionally, how may the dignity of home ownership, no matter how modest, including objects such as one's own yard, often fenced off with whatever materials are available, inform a safer reality? As such, posthumanism may help to bridge local and expert knowledge by taking notions of local "ignorance" out of the equation.

Yet disaster studies scholars continually reiterate the distinction between nature and culture by way of the dichotomy between hazards and vulnerability. If we were to argue, as we have been, that "all disasters are humanmade" then we are in fact saying that there exists a "natural world" (nature) outside of human activity (that is, culture). Similarly, the concepts or paradigms of either hazard or vulnerability, actually imply one another, when we employ a Laclauian logic. Laclau (1990, p. 8) notes that: "the social never manages to fully constitute itself as an objective order." It is always dependent on a constitutive outside to which it is implicitly or explicitly compared. Stating affiliation to the one paradigm cannot fully constitute that paradigm, as the other paradigm is already implied and, as such, forms the former's constitutive outside. In simple terms, this means that vulnerability cannot exist without reference to hazard. Similarly, ascribing all disasters to culture, as is commonplace today, inadvertently recognizes nature as something to be contended with. These two paradigms are continually implicitly or explicitly juxtaposed by disaster scholars. Therefore, the "vulnerability paradigm" remains perennially welded to the "hazard paradigm." The latter has always been implied in the former and significantly, so too has the nature-culture distinction. Stated even differently, to argue that all disasters include a human influence does not refute the potential of nonhuman involvement. What we have been missing is what lies between these two juxtaposed categories. Posthumanism, as briefly elaborated above, helps us to see this.

Linking back to the political nature of disasters, we may state that how the complexities of nature-culture interaction and integration unfolds, morphs, and stagnates is a function of power. This type of power is-borrowing from Digeser (1992) - the power conceived of earlier in this article, namely deliberate and inadvertent influence. This is exactly why some aspects of vulnerability remain inconceivable, no matter how much we lament the supposed fact that disasters are preventable. We can simply do our best in light of complexity and imperfect knowledge. In this regard Kelman (2020), in a book that introduces the vulnerability paradigm to an audience beyond disaster studies, also acknowledges that we cannot address all vulnerabilities all the time.

To properly dispense with notions of nature and culture, we might reframe as a singular ecology what has hitherto been known as dense economic, political, social, cultural, and environmental realities and processes. The point is that we must understand our various realities as part of a complex and infinitely connected and dynamic whole-a singular ecology. One singular ecology might work well at the ontological level. The pragmatism described below, however, might require contextually justifiable epistemological alternatives, which might entail a "temporary suspension of ontology," to serve local needs. The fact that the world is interconnected does not mean it is uniform in all contexts. Therefore, imposing such uniformity on each and every context will likely reproduce the unwanted aspects of the abovementioned impasse and work against the objectives of the petition.

\section{Towards a Pragmatic Political Ecology of Well- Being}

If we were to view the planet as an interconnected ecology and simultaneously acknowledge that disaster reduction is indeed fundamentally political, then the established tradition of political ecology might be a useful way of framing the problem of disaster. In the natural sciences, the term ecology has a quite specific definition: It is the study of the interrelationships between living organisms and their physical environment (Walker 2005). Given the discussion thus far, we may use this definition of a system of organisms and their physical environment and elaborate it to include humans. But ours is not a political ecology that distinguishes between the political (humans) and the ecological (nature). It is a political ecology that takes as its sine qua non the politics of well-being of, and within, a singular ecology. As mentioned, diverse processes and flows at various scales affect every context within this ecology in different ways. This diversity of contexts might require politics through advocacy, negotiation, and/or pressure through the likes of popular mobilization in diverse forms at various levels. Different local populations might, for example, find allies facing similar problems elsewhere. It is here where pragmatism helps us guide the politics required within this ecology.

Without proper theoretical grounding, "pragmatism" and "well-being" might become rather loose terms open to 
all sorts of unwanted mobilizations. In philosophical terms, pragmatism is antifoundational. It therefore does not subscribe to one single coherent theory of how the world is constituted. Instead, interventions are based on what is deemed appropriate in a given context. What is appropriate, however, needs at least some grounding. The manner in which I will ground pragmatism and well-being, draws on the work of Rorty (1989).

I define well-being in terms of the most pressing needs of different segments of the ecology. Such a definition arguably makes sense given the complex and dynamic flows throughout the contemporary ecology. Disaster might not always be the primary concern of particular communities, although this conclusion follows logically from the recent petition, which emphasizes local needs. This conclusion also follows from the work of authors such as Becker and Tehler (2013), who in the process of risk assessment first of all ask communities: What is important? None of this suggests that disaster reduction is not an important pursuit. The practice should be contextualized, however, and researchers should be as open-minded as possible.

By drawing on Rorty (1989) we may further answer the question: What is pragmatism in aid of? We may also consider how to avoid a type of "anything goes" interpretation of pragmatism. Rorty (1989) also gives us a clear yet succinct and sufficiently broad perspective on wellbeing. His praxis follows from the understanding that words do not represent reality (Rorty 1989). They shape reality. Rorty (1989) urges us to redescribe our past vocabularies and how we might relate the present to an imagined future (Bernstein 1990). We may therefore say that Rorty (1989) allows us a way of "thinking a new world" at every instance of micropolitics. This approach is quite different from the colonialism and the "antipolitics machine" of developmentalism described by Escobar (1995) and Ferguson (1990), largely because its logic is anti-instrumentalist. In other words, Rorty (1989) forces us to think more openly about means and ends in context and beyond routine and standardized developmental activities.

Rorty (1989) also notes that each of us has an unbendable set of principles by which we make decisions, a socalled final vocabulary. He offers us his final vocabulary, which is sufficiently clear as a guideline for disaster studies, but not so constrictive that it might defeat the objective of being open to local perspectives. Rorty (1989) describes himself as a liberal ironist. Being an ironist suggests something on which you are not willing to compromise. Rorty (1989) is an unwavering liberal. Therefore, all pragmatic action has to conform to the principles of liberalism. The choice of liberalism (or any ideological perspectives for that matter) leaves us with a potential conceptual problem. The broad set of ideas that has over the years been placed under the rubric of liberalism has so many dimensions that using liberalism as a benchmark for pragmatic action may at best be meaningless and at worst serve a type of neocolonialism. This choice of vocabulary was possibly brought on by the fact that Rorty was an American, a context where "liberal" is arguably often code for anything progressive (granted that Chicago School economics might be an obvious exception). Luckily, Rorty (1989) is quite clear on what he means by liberal. To be liberal according to him is "to despise any harm to any person." Thus, he offers us a relatively precise definition of liberal ironism. Based on the analysis above, we might extend this definition somewhat and define our standard for pragmatic political ecology as "any action or inaction that attempts to prevent harm to the broader ecology or any aspect thereof." Well-being similarly may be linked to the absence of harm, but it is a necessary addition, so we do not get stuck on the instrumental rationality of disaster reduction. Instead, we may ask: What is harm reduction in this context and how do we effect it? There are potential internal tensions in this conceptualization. Harm to some part of the ecology might sometimes be required to prevent harm to others. But the same would equally be true for "vulnerability reduction." This problematic might require more theoretical work, in terms of the do no harm literature. But, that is beyond the scope of the current article. For now, we might draw on Rorty's (1989) basic premise by using concepts, preferably by those affected by disasters or other challenges, to shape new realities.

In accordance with the ethos of the petition, the purpose here is not to propose any particular course of action across time and space, beyond the suggested pragmatism based on the liberal ironist final vocabulary. A few additional comments might be made based on the ontology of a singular ecology. As mentioned, this ontology may not always translate into universal epistemologies. Haraway's (1988) notion of situated knowledge may be instructive here. Much like the authors of the petition, she notes that no knowledge is complete. Knowledge is always situated and contingent. What is considered the best ways to achieve important goals may also be a function of situated knowledge and thus inform the previous mentioned temporary "suspension of ontology." The notion of situated knowledge therefore offers a significant conceptual grounding for heeding the principles of the petition. Whereas appropriate posthumanism may inform praxes, by advising us to draw on contextually appropriate knowledges.

We may superimpose various conceptual frameworks onto the perspectives set out in the petition and in this article. While the article has already covered, nonexhaustively, some suggestions for recognizing local knowledge, I will now highlight one set of approaches pertaining to the 
complexity of the flows that permeate the contemporary singular ecology. Thereafter, I will briefly touch on one important principle that might be valuable in both instances.

In recent years there has been an interest in disaster studies in Sweden and South Africa, which foregrounds systems approaches to disaster reduction (Becker 2009; Coetzee and Van Niekerk 2018). Systems theories, of which there are many, aim to recognize the immense complexity, including the complexity of causal relations within the world we inhabit. They also allow for reflexive thought, which suspends instrumental rationality, for the sake of more pragmatic outcomes. Coetzee and van Niekerk (2018), quite clearly demonstrate such reflexive thought when they ask: Should all disasters be reduced? This is an extremely important question, given the potential unintended consequences of intervention. There may however also be at least one potential danger for the types of politics conceived of through systems approaches. If systems are viewed as complex and adaptive, then researchers not deploying the reflexive thinking noted above might fall into a functionalist trap. According to such logic all that is required is for adaptation to be steered towards "equilibrium," where the system seemingly "functions." We may make many empirically grounded arguments against such a search for an ultimate telos (ultimate aim). Suffice it to say here that the complexity of the ecology does not allow for such a functioning system. All systems and subsystems simultaneously function and dysfunction. Our objective should be to intervene into the latter as best we can. Systems Theory according to Wolfe (2010, p. 15) in his book What is Posthumanism? is precisely valuable in the context of posthumanism for its "openness from closure," which is also commensurable with the pragmatic approach in which this article has essentially been anchored.

It is this shared underlying logic that appeals to me as an appropriate basis for rendering new worlds with less suffering. I understand that realists might find this radical contingency frustrating and potentially dangerous. I would, however, maintain that all ideas, perhaps even more so ideas that seek to transcend through a singular cogent set of assumptions, are often open to manipulation and adverse consequences.

To best deal with complexity, disaster reduction requires the best possible research designs, data, and interpretive tools. These will often draw on a set of tools and techniques developed and negotiated by concerned stakeholders. Examples might include local researchers, external researchers, and authorities. In order to deliver the best and most useful knowledge and outcomes based on local needs the process cannot be rushed. Researchers should heed what Stengers (2018) calls slow science. It is important that external researchers find ways of dealing with the "publish or perish" phenomenon and quests for personal prestige in ways that do not harm the quality of the research where it actually matters. There is often too much at stake in terms of potential harms to life and limb and financial setbacks. One approach might be to produce parallel publications. Some more jargon-laden papers could be aimed at academic audiences. But, the most important research output, subject to collaboration, should be useful in the local where it has been produced and to those by whom and for whom it was produced.

\section{Conclusion}

This article has considered the recent petition for reform within disaster studies as an opportunity to address the nature-culture divide within the field. This nature-culture distinction potentially oversimplifies disaster and limits our ability to comprehend the complex dynamics of disaster risk. As such, it also limits the conceivable and actionable options available to at risk communities and especially local authorities. The article has drawn on insights from posthumanism, especially at lower levels of analysis, while subsuming all disaster reduction under the rubric of pragmatist philosophy. In the process I have conceived of a pragmatic political ecology of well-being within a singular ecology. My approach has been distinguished from the seemingly endless juxtaposition of hazard and vulnerability. This juxtaposition has over the past nearly 50 years been useful in effecting a constructive mind shift in at least some academic, practice, and policy circles. The downside of the dominant vulnerability perspective, when taken to its logical conclusion, is the incredible set of implications for political action it places on researchers and practitioners. The inability to deal with these implications has rendered blame a de facto prevailing tool of this perspective. But reliance on blame closes off the possibility for constructive deliberation, especially at the micro level and at a very early stage in discussion, through the cognitive frames with which practitioners and researchers approach diverse contexts.

Only if we understand that disasters are a normal part of our singular ecology, as defined in this article, can we begin to approach each context on its own terms. What actionable knowledge we do and do not have differs between contexts. Some contexts might benefit by drawing on posthumanism. In other contexts, a more traditional vulnerability toolkit might be equally or even more valuable.

Having advocated for the merits of the reform petition, I do whole-heartedly agree with Wisner (2020) as to the dangers of the vocabulary of community participation; not 
that we do not need it. We certainly do and lots of it, but this participation cannot be a cop-out for authorities. Participation cannot take on a form akin to a neoliberal responsible self, where communities are always expected to fend for themselves. My argument has not been that there is no use in placing pressure on authorities who neglect their responsibilities and that macro-level root causes should not be resisted, fiercely. While the latter is extremely important, it is a more generic pursuit extending beyond disaster reduction. Participation for disaster reduction instead should be viewed as an active and dynamic politics of agenda setting. Such a politics would be a means by which the state can be held accountable and through which diverse processes of negotiation, influence, alliance formation, or demonstration can be brought to life. We should also bear in mind, as the petition does, that there is a potential contradiction between participation and fashionable development buzzwords, when external experts are closed off to local perspectives (and vice versa). In this regard, the language of posthumanism may also be useful camouflage for radical and open-ended politics, at least at the level of the funding proposal.

To conclude with a final word of caution might be apt. Even as early as the 1970s some of the pioneers of the disaster studies field emphasized many of the issues raised in the petition (Davis 2019; Gaillard 2019). Yet, decades later many disaster scholars apparently needed to be reminded of these ideals once again. As noted, we live in a complex ecology. This makes interventions extremely tricky. We will make mistakes. Those missteps can be forgiven if they were initiated in good faith. But we also live in an extremely individualist world, especially in the West and westernized settler colonial contexts. There is extreme competition for all jobs, including those in state, development, and academic institutions and agencies. This is also an era where publication metrics often play a major role in the evaluation of research. Therefore, the threat remains of superficial and extractive research largely aimed at professional gains. This article has only briefly considered remedial strategies in this regard, in the form of parallel publications. More innovative strategies to ensure professional survival should be contemplated at length, while truly heeding the call to action and inclusion advocated in the petition.

Acknowledgements I would like to thank Ilan Kelman and three anonymous reviewers for their constructive and insightful comments on earlier drafts of this paper. All interpretations and mistakes are of course my own.

Open Access This article is licensed under a Creative Commons Attribution 4.0 International License, which permits use, sharing, adaptation, distribution and reproduction in any medium or format, as long as you give appropriate credit to the original author(s) and the source, provide a link to the Creative Commons licence, and indicate if changes were made. The images or other third party material in this article are included in the article's Creative Commons licence, unless indicated otherwise in a credit line to the material. If material is not included in the article's Creative Commons licence and your intended use is not permitted by statutory regulation or exceeds the permitted use, you will need to obtain permission directly from the copyright holder. To view a copy of this licence, visit http://creativecommons. org/licenses/by/4.0/.

\section{References}

Bankoff, G. 2001. Rendering the world unsafe: "Vulnerability" as Western discourse. Disasters 25(1): 19-35.

Becker, P. 2009. Grasping the hydra: The need for a holistic and systematic approach to disaster risk reduction. Jàmbá: Journal of Disaster Risk Studies 2(1): 12-24.

Becker, P., and H. Tehler. 2013. Constructing a common holistic description of what is valuable and important to protect: A possible requisite for disaster risk management. International Journal of Disaster Risk Reduction 6: 18-27.

Bernstein, R.J. 1990. Rorty's liberal utopia. Philosophy and Politics 57(1): 31-72.

Castells, M. 1996. The network society. London: Blackwell.

Coetzee, C., and D. van Niekerk. 2018. Should all disaster risks be reduced? A perspective from the systems concept of the edge of chaos. Environmental Hazards 17(5): 470-481.

Davis, I. 2019. Reflections on 40 years of disasters, 1977-2017. Disasters 43(S1): S61-S82.

Dean, M. 1998. Risk, calculable and incalculable. Soziale Welt 49(1): $25-42$.

Digeser, P. 1992. The fourth face of power. The Journal of Politics 54(4): 977-1007.

Escobar, A. 1995. Imagining a post-development era. In Power of development, ed. J. Crush, 211-227. London: Routledge.

Ferguson, J. 1990. The anti-politics machine: Development, depoliticization, and bureaucratic power in Lesotho. Cambridge: Cambridge University Press.

Flint, C.G., and A.E. Luloff. 2005. Natural resource-based communities, risk, and disaster: An intersection of theories. Society \& Natural Resources 18(5): 399-412.

Freudenburg, W.R. 1996. Risky thinking: Irrational fears about risk and society. Annals of the American Academy of Political and Social Science 545(1): 44-53.

Gaillard, J.C. 2019. Disaster studies inside out. Disasters 43(S1): S7S17.

Gaillard, J.C., B. Alexander, P. Becker, K. Blanchard, L. Bosher, F. Broines, J.R. Cadag, K. Chmutina, et al. 2019. Power, prestige \& forgotten values: A disaster studies manifesto. https://www. ipetitions.com/petition/power-prestige-forgotten-values-a-disas ter. Accessed 14 Apr 2020.

Haraway, D. 1988. Situated knowledges: The science question in feminism and the privilege of partial perspective. Feminist Studies 14(3): 575-599.

Haraway, D. 2004. Promises of monsters: A regenerative politics for inappropriate/d others. In The Haraway reader, ed. D. Haraway, 63-124. New York: Routledge.

Hewitt, K. 1997. Regions of risk: A geographical introduction to disasters. Longham: Addison Wesley.

Higgs, P. 1998. Risk, governmentality and the reconceptualization of citizenship. In Modernity, medicine and health, ed. G. Scambler, and P. Higgs, 177-198. London: Routledge.

IPCC (Intergovernmental Panel on Climate Change). 2007. Summary for policymakers. Contribution of Working Group II to the Fourth Assessment Report of the Intergovernmental Panel on 
Climate Change. http://www.ipcc.ch/pdf/assessment-report/ar4/ wg2/ar4-wg2-spm.pdf. Accessed 27 Oct 2009.

Katanha, A., and D. Simatele. 2019. Natural hazard mitigation strategies review: Actor-network theory and the eco-based approach understanding in Zimbabwe. Jàmbá: Journal of Disaster Risk Studies 11(1): 79-87.

Kelman, I. 2010. Natural disasters do not exist (Natural hazards do not exist either) Version 3, 9 July 2010 (Version 1 was 26 July 2007). http://www.ilankelman.org/miscellany/NaturalDisasters. doc. Accessed 24 Apr 2020.

Kelman, I. 2020. Disaster by choice. Oxford: Oxford University Press.

Laclau, E. 1990. New reflections on the revolution of our time. New York: Verso.

Latour, B. 1993. We have never been modern. New York: Harvester.

Lewis, J. 1989. Sea level rise: Some implications for Tuvalu. Environmentalist 9: 269-275.

Lewis, J., and I. Kelman. 2012. The good, the bad and the ugly: Disaster risk reduction (DRR) versus disaster risk creation (DRC). PLoS Currents: Disasters. https://doi.org/10.1371/ 4f8d4eaec6af8.

Maskrey, A. 1989. Disaster mitigation: A community based approach. Oxford: Oxfam.

Oliver-Smith, A. 2013. A matter of choice: Editorial. International Journal of Disaster Risk Reduction 3: 1-3.

O'Keefe, P., K. Westgate, and B. Wisner. 1976. Taking the naturalness out of natural disasters. Nature 260(5552): 566-567.

Rorty, R. 1989. Contingency, irony and solidarity. Cambridge: Cambridge University Press.

Stengers, I. 2018. Another science is possible: A manifesto for slow science. Translated by Stephen Muecke. Cambridge: Polity.

Van Riet, G. 2017. The institutionalization of disaster risk reduction: South Africa and neoliberal governmentality. London: Routledge.
Waschinger, G., O. Renn, C. Begg, and Kuhlicke. 2013. The risk perception paradox-implications for governance and communication of natural hazards. Risk Analysis 33(6): 1049-1065.

Walker, P.A. 2005. Political ecology: Where is the ecology?. Progress in Human Geography 29(1): 73-82.

Wisner, B. 2001. Capitalism and the shifting spatial and social distribution of hazard and vulnerability. Australian Journal of Emergency Management 16(2): 44-50.

Wisner, B. 2019. Disaster studies at 50: Time to wear bifocals? In Disaster research and the second environmental crisis, ed. J. Kendra, S.G. Knowles, and T. Wachtendorf, 47-68. Berlin: Springer.

Wisner, B. 2020. Five years beyond Sendai: Can we get beyond frameworks?. International Journal of Disaster Risk Science 11(2): 239-249.

Wolfe, C. 2010. What is posthumanism?. Minneapolis: University of Minnesota Press.

WCDRR (World Conference on Disaster Reduction). 2005. Hyogo framework for action 2005-2015: Building the resilience of nations and communities to disasters. Report of the World Conference on Disaster Reduction, 18-22 January 2005, Kobe, Hyogo, Japan. http://www.unisdr.org/2005/wcdr/intergover/offi cial-doc/L-docs/Hyogo-framework-for-action-english.pdf. Accessed 24 May 2013.

WCDRR (World Conference on Disaster Risk Reduction). 2015. Sendai framework for disaster risk reduction 2015-2030. https:// www.preventionweb.net/files/43291_sendaiframeworkfordrren. pdf. Accessed 19 Apr 2020.

Xu, D., E. Liu, X. Wang, H. Tang, and S. Liu. 2018. Rural households' livelihood capital, risk perception, and willingness to purchase earthquake disaster insurance: Evidence from Southwestern China. International Journal of Environmental Research and Public Health 15(7): 1319-1338. 